\title{
Active Ankle Point Orthosis Based On Artificial Muscle Fibers
}

\author{
Axel Herrmann*, Boris Marx and Lars Bostan \\ Faserinstitut Bremen e.V. Gebäude IW3 Am Biologischen Garten 228359 Bremen, Germany \\ *Corresponding author: Axel Herrmann, Faserinstitut Bremen e.V. Gebäude IW3 Am Biologischen Garten 228359 \\ Bremen, Germany
}

\begin{tabular}{lll}
\hline ARTICLE INFO & & ABSTRACT \\
\cline { 1 - 1 } Received: 幽 April 17, 2020 & & $\begin{array}{l}\text { Citation: Axel Herrmann, Boris Marx, Lars Bostan. Active Ankle Point Orthosis Based } \\
\text { On Artificial Muscle Fibers. Biomed J Sci \& Tech Res 27(2)-2020. BJSTR. MS.ID.0044847. }\end{array}$ \\
Published: 幽 April 29, 2020 & &
\end{tabular}

\section{Introduction}

One of the most important forms of human movement is walking. The foot-shank-complex with the associated ankle joint has a central function. Due to numerous neurological and muscular diseases or injuries, walking can be negatively affected. The care of people with those impairments is made by orthopedic and rehabilitation technologies. For example, orthosis are attached to the ankle joint from the outside. However, commercially available orthoses often cannot sufficiently help to develop a physiologically healthy walk. Users are often severely restricted in their mobility. Out-of-rounds movements lead to further problems with the musculoskeletal system and another treatment can be necessary. Furthermore, pressure marks can arise through the orthoses. The aim of the research project "Aktiv Orthese" is the development of an active, soft ankle-point-orthosis. For this purpose, a system is developed which allows a physiologically normal walk. Thus enables a walk that is biomechanically natural and functional. The innovative ankle-point-orthosis is intended to support the patient fully automatically in the walking motion. At the same time it shall be so light and flexible that it does not disturb or restrict the wearer when moving. This is to be achieved by the development of a textile structure that does not require any rigid elements.

(Figure 1) shows the basic idea of the active ankle-pointorthosis. The essential function is to help lift the patient's foot and to prevent uncontrolled fall of the forefoot after heel strike. The needed actuator in the form of artificial muscles based on polymer fibers is developed at the Faserinstitut Bremen. The requirement is that on the one hand it is powerful enough to lift the patient's foot while walking; on the other hand it is light and flexible. The functional principle of the artificial muscles is based on the material properties of polymer fibers: Highly drawn, partially crystalline polymer filaments often have a negative coefficient of thermal expansion in fiber direction. They contract with increasing temperature. When such filaments are twisted, the effect results in torsion of the filament. Responsible for thermal contraction are the molecular structures, which mean crystalline parts of high orientation. They are spirally located in the filament.

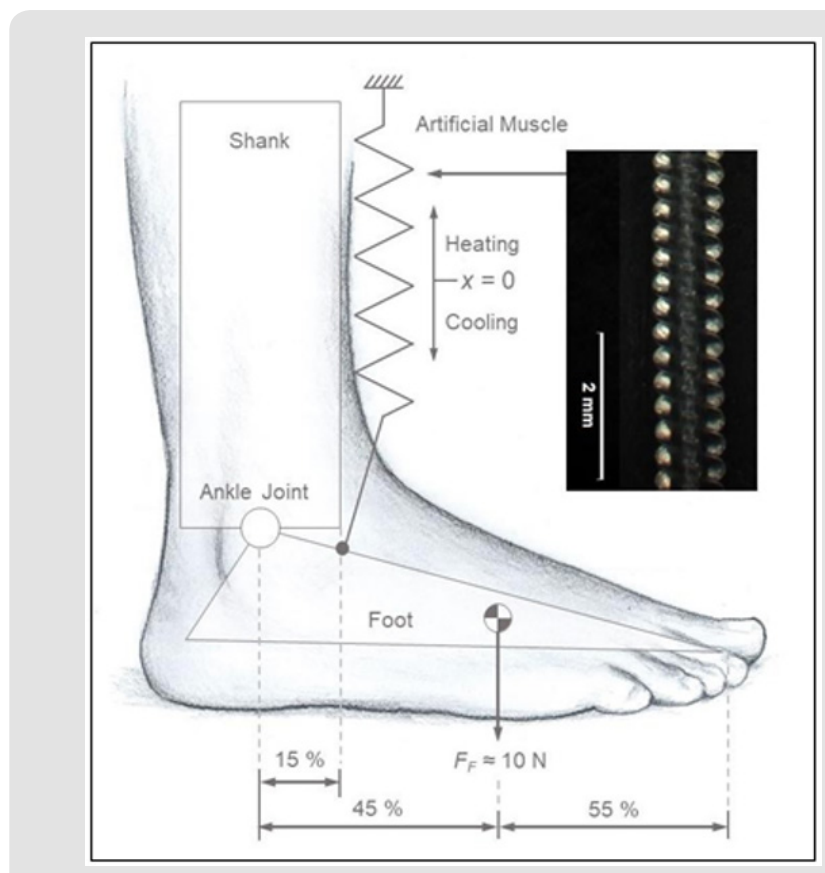

Figure 1: Basic idea of the active ankle-point-orthosis. 
With a helical arrangement of the twisted filament and use of the heat-induced torsion, a shortening of the spiral formed can be realized analogous to a helical spring. The functional principle of the artificial muscles has already been described in numerous publications [1-3]. This article presents the concrete application, the manufacturing and the investigation of the properties. The artificial muscles are manufactured on a specially developed structure. The monofilament material used is Perlon. Different muscle diameters can be generated. The vertically suspended weighted monofilament is twisted by an electric motor. By recording the number of revolutions with a magnetic counter, the length of the muscles can be calculated. By changing the weight, the spring rate of muscle can be determined. After twisting, the artificial muscles are thermo-fixed. On the one hand, thermo mechanical and, on the other, dynamic behavior is of major importance for the application

ISSN: 2574-1241

DOI: $10.26717 / B J S T R .2020 .27 .004487$

Axel Herrmann. Biomed J Sci \& Tech Res

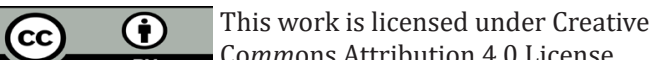

Submission Link: https://biomedres.us/submit-manuscript.php of artificial muscles as an actor in orthoses. The results show the potential of artificial fibers based on twisted polymer fibers for use in an active orthosis. With the experiments performed on the artificial muscles, the strength, the path and the dynamics of the system can be measured and determined.

\section{References}

1. Haines C S, Lima MD, Li N, Geoffrey M Spinks, Javad Foroughi, et al. (2014) Artificial Muscles from Fishing Line and Sewing Thread. Science 343(6173): 868- 872 .

2. Moretti G, Cherubini A, Rocco V (2015) Experimental characterization of a new class of polymeric-wire coiled transducers. Behavior and Mechanics of Multifunctional Materials and Composites pp. 9432.

3. Saharan L, Tadesse Y (2019) Novel twisted and coiled polymer artificial muscles for biomedical and robotics applications. Materials for Biomedical Engineering: Nan biomaterials in Tissue Engineering p. 4575.

$\begin{array}{ll}\text { BIOMEDICAL } & \text { Assets of Publishing with us } \\ \text { RESEARCHES } & \text { - Global archiving of articles } \\ \text { - Immediate, unrestricted online access } \\ \text { - Rigorous Peer Review Process } \\ \end{array}$

